\title{
The Reactions of 3-Chloro- and 3-Bromo-2,4-pentanedione with Malonitrile and with Ethyl Cyanoacetate
}

\author{
G UN NEL WEST Ö Ö
}

Institute of Organic Chemistry, University of Lund, Lund, Sweden

\begin{abstract}
2-Amino-3-cyano-4-acetyl-5-methylfuran (I a), 2-amino-3-ethoxycarbonyl-4-acetyl-5-methylfuran (I b) and 2-amino-3-ethoxycarbonyl4,4,5-triacetyl-6-methylpyran (II) have been prepared.
\end{abstract}

When the sodium salt of 3-chloro-2,4-pentanedione reacts with malonitrile W or ethyl cyanoacetate in ethanol - water solution, cyclization of the primarily formed III a, b occurs with formation of the neutral compounds, 2-amino3-cyano-4-acetyl-5-methylfuran (I a) or 2-amino-3-ethoxycarbonyl-4-acetyl-5methylfuran (I b).

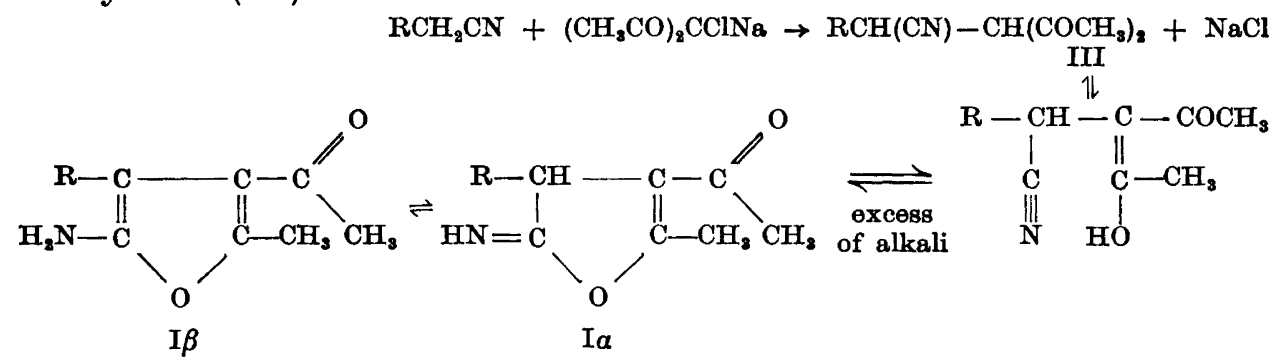

a. $\mathrm{R}=\mathrm{CN}$

b. $\mathrm{R}=\mathrm{COOC}_{\mathbf{2}} \mathrm{H}_{6}$

I $\mathrm{a}$ and $\mathrm{b}$ are stable (cf. unsubstituted 2-aminofuran which is very unstable), probably on account of the resonance possibilities offered by the 3-cyanoor the 3-ethoxycarbonyl groups, e.g.<smiles></smiles>

Acta Chem. Scand. 13 (1959) No. 4 
The IR absorption curve of $\mathrm{I}$ a (in $\mathrm{KBr}$ and in nujol) has one single nitrile band at $2175 \mathrm{~cm}^{-1}$. This means a displacement of about $75 \mathrm{~cm}^{-1}$ from the unconjugated nitrile band at $2250 \pm 10 \mathrm{~cm}^{-1}$, indicating a strong resonance effect on the nitrile group ${ }^{1}$. A nujol suspension of the product shows absorption at 3100 and $3250 \mathrm{~cm}^{-1}$, which is within the region characteristic of associated amino groups. After equilibration with $\mathrm{D}_{2} \mathrm{O}, \mathrm{ND}_{2}$-bands at 2330 and $2500 \mathrm{~cm}^{-1}$ were obtained. Thus I a $\beta$ is probably the main structure of the product formed. With o-nitrobenzaldehyde a Schiff's base can be prepared from I a, and with 2,4-dinitrophenylhydrazine a 2,4-dinitrophenylhydrazone.

The IR spectrum of $I \mathrm{~b}$ in potassium bromide has no nitrile band and shows the expected $\mathrm{NH}_{2}$-bands at 3200 and $3390 \mathrm{~cm}^{-1}$.

The basic character of the amino group of $I a, b$ is so weak that the products cannot be titrated with perchloric acid in glacial acetic acid. Excess of alkali dissolves $\mathrm{I} a$ and $\mathrm{b}$ with opening of their furan rings. On acidification ring closure with reformation of I a and I b takes place, but only in low yields because of alkaline hydrolysis of the nitrile and carbethoxy groups.

The reaction of the sodium salt of 3-bromo-2,4-pentanedione with malonitrile is analogous to the reaction described above of the corresponding chloro compound, I a being formed though in lower yield. The reactions of ethyl cyanoacetate with 3-bromo-2,4-pentanedione and with 3-chloro-2,4-pentanedione, however, are essentially different. With the bromo compound a pyran derivative, II, is formed evidently according to the equations:

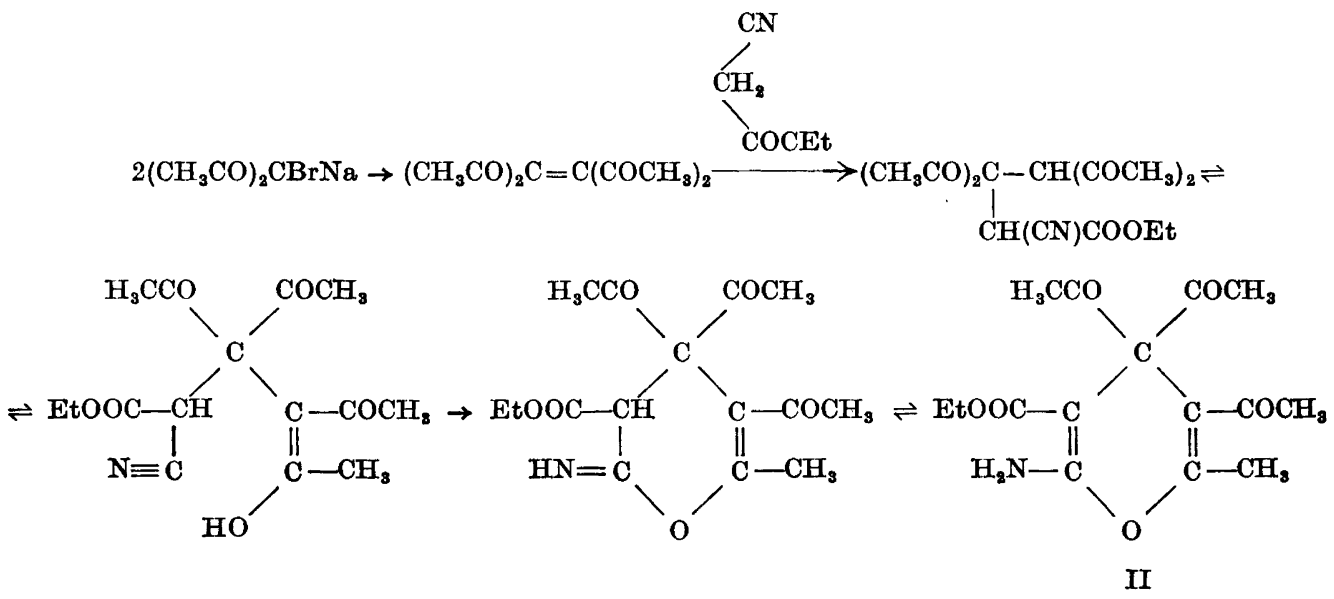

The IR absorption curve of the product (in $\mathrm{KBr}$ ) has no nitrile band but $\mathrm{NH}_{2}$ stretching bands at 3225 and $3325 \mathrm{~cm}^{-1}$. The amino group is basic enough to be titrated with perchloric acid in glacial acetic acid, though not very sharply.

It should be mentioned that the reaction of 3-chloro (or bromo)-2,4pentanedione with cyanoacetamide in alkaline solution ${ }^{2}$ follows other pathways than the reactions described above, pyridine derivatives being formed according to the equations

Acta Chem. Scand. 13 (1959) No. 4 


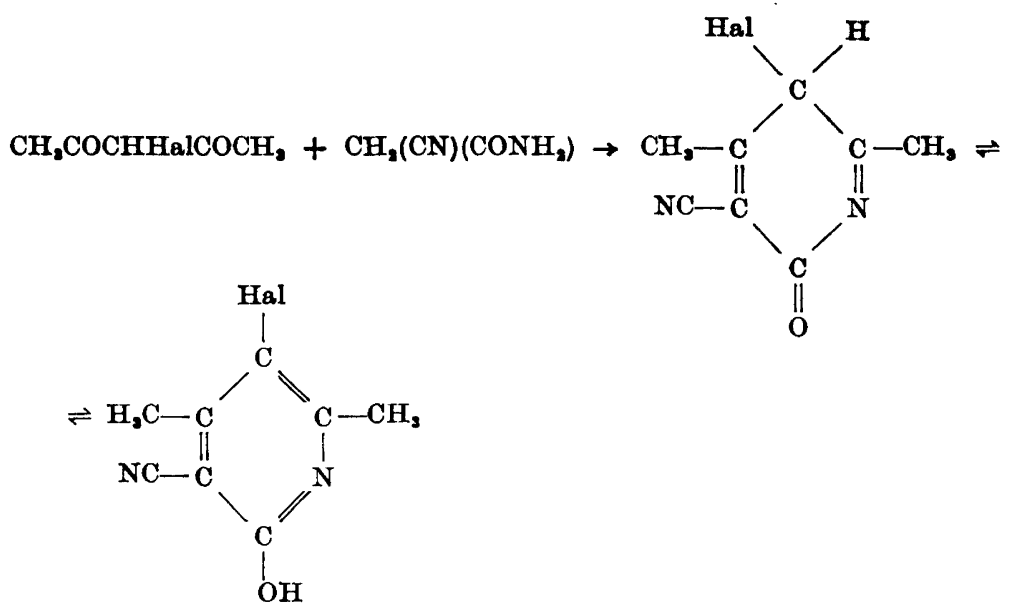

EXPERIMENTAL

Preparation of 2-amino-3-cyano-4-acetyl-5-methylfuran (I a). 3-Chloro-2,4-pentanedione (2.69 $\mathrm{g}$ ) and malonitrile $(1.32 \mathrm{~g})$ were dissolved in ethanol $(10 \mathrm{ml})$, and sodium hydroxide (8.26 ml of $2.42 \mathrm{~N}$ solution) was added. Colourless crystals of I a started separating immediately. The next day they were collected by filtration and washed with $50 \%$ ethanol. Yield: $3.05 \mathrm{~g}, \mathrm{~m}$. p. about $240^{\circ}$ (decomp.). The product can be recrystallized from ethanol. (Found: $\mathrm{C} 58.5 ; \mathrm{H} 4.85 ; \mathrm{N} 17.1 ; \mathrm{O}, 19.5$. Calc. for $\mathrm{C}_{8} \mathrm{H}_{8} \mathrm{~N}_{2} \mathrm{O}_{2}$ : $\mathrm{C}$ 58.5; $\mathrm{H} 4.9 ; \mathrm{N} 17.1 ; \mathrm{O}$ 19.5.)

2,4-Dinitrophenylhydrazone: M.p. $166-168^{\circ}$ (decomp.) (Found: C 48.9; H 3.7; N 24.3; $\mathrm{O}$ 23.4. Calc. for $\mathrm{C}_{14} \mathrm{H}_{12} \mathrm{~N}_{6} \mathrm{O}_{5}$ : $\mathrm{C} 48.8 ; \mathrm{H}$ 3.5; $\mathrm{N}$ 24.4; $\mathrm{O}$ 23.2.) Schiff's base with o-nitrobenzaldehyde (Found: $\mathrm{C} 60.6 ; \mathrm{H} 4.0 ; \mathrm{N} 14.0$. Calc. for $\mathrm{C}_{15} \mathrm{H}_{11} \mathrm{~N}_{3} \mathrm{O}_{4}: \mathrm{C} 60.6 ; \mathrm{H}$ 3.7; N 14.1).

Preparation of 2-amino-3-ethoxycarbonyl-4-acetyl-5-methylfuran ( $I$ b). 3-Chloro-2,4pentanedione $(2.69 \mathrm{~g})$ and ethyl cyanoacetate $(2.26 \mathrm{~g})$ were dissolved in ethanol $(7 \mathrm{ml})$. When sodium hydroxide $(8.26 \mathrm{ml}$ of $2.42 \mathrm{~N}$ solution) was added, colourless crystals of I b soon started separating. The following day the product was filtered and washed with $50 \%$ ethanol. Yield: $3.30 \mathrm{~g}$; m. p. after recrystallization from ethanol: $136^{\circ}$. (Found: C 57.0; $\mathrm{H} 6.2 ; \mathrm{N} \mathrm{6.7;} \mathrm{O} 30.1$. Calc. for $\mathrm{C}_{10} \mathrm{H}_{13} \mathrm{NO}_{4}$ : C 56.9; $\mathrm{H} \mathrm{6.2;} \mathrm{N} \mathrm{6.6;O} \mathrm{30.3.)}$

Preparation of 2-amino-3-ethoxycarbonyl-4,4,5-triacetyl-6-methylpyran (II). Bromine $(3.2 \mathrm{~g})$ was added with stirring to a cooled $\left(12^{\circ}\right)$ solution of 2,4 -pentanedione $(2.0 \mathrm{~g})$ in $8.26 \mathrm{ml}$ of $2.42 \mathrm{~N}$ sodium hydroxide solution and $15 \mathrm{ml}$ of ethanol. After cooling the solution to $8^{\circ}$, sodium hydroxide $(4.1 \mathrm{ml}$ of $2.42 \mathrm{~N}$ solution) was added and - one minute later - ethyl cyanoacetate $(1.38 \mathrm{~g})$ and another $5.0 \mathrm{ml}$ of sodium hydroxide solution. After $5 \mathrm{~h}$ the precipitate formed was filtered and washed with $50 \%$ ethanol. Yield: $0.56 \mathrm{~g}$; m.p. $166^{\circ}$ (decomp.). (Found: C 58.2; H 6.2; N 4.7; O 30.9; mol. wt 320. Calc. for $\mathrm{C}_{16} \mathrm{H}_{10} \mathrm{NO}_{6}$ : C 58.2; $\mathrm{H}$ 6.2; $\mathrm{N} 4.5 ; \mathrm{O} 31.0 ;$ mol. wt 309.)

The analyses were performed by Mikroanalytisches Laboratorium im Max-PlanckInstitut für Kohlenforschung, Mülheim, Germany. Dr. Andreas Rosenberg, University of Uppsala, carried out the IR messurements.

The author wishes to thank Statens naturvetenskapliga forskningsr\&d for financial support.

\section{REFERENCES}

1. Kitson, R. E. and Griffith, N. E. Anal. Chem. 24 (1952) 334.

2. Coover, H. W. and Bowman, N. J. U.S. Patent 2.481.573; Sept. 13, 1949.

Received January 7, 1959.

Acta Chem. Scand. 13 (1959) No. 4 